\title{
DESIGN FOR CHANGE: FIVE PROXIES FOR RESILIENCE IN THE URBAN FORM
}

\author{
Alessandra Feliciotti \\ Ombretta Romice \\ Sergio Porta
}

\begin{abstract}
The sheer complexity and unpredictability characterizing cities challenges the adequacy of existing disciplinary knowledge and tools in urban design and highlights the necessity to incorporate explicitly the element of change and the dimension of time in the understanding of, and intervention on, the form of cities. To this regard the concept of resilience is a powerful lens through which to understand and engage with a changing world. However today resilience is addressed by urban designers only superficially, and an explicit effort to relate elements of urban form to resilience principles is still lacking, representing a great limit for urban designers, as form is their elective medium of intervention in the urban system. As first steps to overcome this gap, we explore in this work the combination of established knowledge in urban morphology and urban design, with knowledge developed in resilience theory and we look at the configuration of, and interdependencies between, different urban elements from the perspective of five proxies of urban form resilience, namely diversity, redundancy, modularity, connectivity and efficiency. After defining each proxy in resilience theory and in relation to urban form, we address them at five different scales which are relevant to urban morphology and urban design: plot, street edge, block, street and sanctuary area / district.
\end{abstract}

Keywords: Urban Design, Resilience, Proxies, Urban morphology, urban form.

\section{INTRODUCTION}

Up to fifty years ago, planners and designers believed that urban problems could be solved with high certainty over the long time (Firley and Grön, 2014). Today, we see cities as extremely complex systems characterized by the dynamic interaction of intermediary nested human, physical and institutional systems (Moench et al., 2011) and by a condition of perpetual disequilibrium (Batty, 2013). This sheer complexity greatly outstrips our ability to make reliable predictions (Holling and Goldberg, 1971) and leaves planners and designers with the seemingly impossible task of making longterm plans in the face of an uncertain future. It challenges the very adequacy of existing disciplinary knowledge and tools in urban design and highlights the necessity to incorporate explicitly the element of change and the dimension of time in the understanding of, and intervention on, the form of cities (Porta and Romice, 2014, Thwaites et al., 2007). The advocated shift is not straightforward. However, over the last three decades, the sustainability agenda already brought important new values, methods and tools in urban design both in theory (Carmona, 2010) and in practice (Rudlin and Falk, 2009), that seem to point in this direction. More recently, the term sustainability was re-formulated in a dynamic dimension as an "inherently moving target" (Novotny et al., 2010 p.141) whose path cannot be charted in advance. At this regard the concept of resilience becomes a way to understand and engage with a 
changing world tuning and adapting our action in the urban system as the "target" of sustainability moves over time.

Resilience and urban design are potentially important allies to meet the challenge of future urbanization (Marcus and Colding, 2014, Feliciotti, in print). Currently, however, partly because resilience remains a relatively new concept in urban design (Hassler and Kohler, 2014), it is addressed to by urban designers only superficially and lacks a clear definition (Allan and Bryant, 2011). Despite resilience theory being "the most promising trans-disciplinary arena in the built environment" (Hassler and Kohler, 2014 p.120), and whilst urban form greatly influences environmental (Mehaffy, 2015), social (Thwaites et al., 2013) and economic (Tachieva, 2010) sustainability in cities, an explicit effort to relate the constitutive elements of urban form to principles of resilience is still lacking. At present, there is no systematic way to account for the distinct morphological contribution of the urban form to resilience. This represents a great limit for urban designers, as form is their elective medium of intervention in the urban system (Marcus and Colding, 2011).

Fortunately the increasing interest on the physical form of cities (Batty and Marshall, 2009), supported by greater data availability and computing techniques (Batty, 2013), and the emergence of a stronger evidence-based approach in urban design research recorded over the last decade, give us means and opportunity of making the concept of resilience more directly expendable in urban design. This paper is a first step in this direction.

In the following pages, the urban form of cities is explored from a resilience perspective. In particular, as resilience is a complex and layered concept, this is looked at by breaking it down into what Carpenter et al. (2005) define as resilience proxies: context-base attributes indirectly inferable to resilience and ascertainable through observation. These are presented with an updated definition that accounts for their role in building resilience in relation to the urban form, combining literature from resilience theory, system ecology and urban design. Finally, after introducing the spatial-temporal scales which make up urban form and are typical of the urban design area of knowledge, each will be discussed in relation to its contribution to the selected proxies.

\section{RESILIENCE PROXIES FOR THE URBAN FORM}

There is currently no agreement in literature on a unified list of proxies encompassing all aspects of resilience: a multidisciplinary review of literature carried out by the authors (Feliciotti et al., 2015), highlighted over 30 attributes associated to resilience across over a selection of more than 40 publications over the last 40 years. From this total, and for the purposes of this study, the 5 most frequently associated to urban form were selected.

\section{Diversity}

Core concept in resilience theory, diversity enables systems to implement multiple coping strategies (Marcus and Colding, 2011), helping them remain relatively stable through change and providing them with higher potential for innovation (Cloete, 2012). Diversity frequently appears in urban design literature in relation to use and geometry of the urban form (Tarbatt, 2012, Montgomery, 1998, Jacobs, 1961). Diversity of uses 
and transport modes is linked to liveability, economic attractiveness and healthier lifestyles (Mehaffy, 2015, Wood and Dovey, 2015). Diversity of form is also important, even beyond any specific function: the very way urban space is divided and subdivided gives places an intrinsic capacity to carry diversity, enabling them to "continue to succeed despite changes in economic conditions, technology and culture" (Montgomery, 1998 p.106) despite some uses change or are lost, also supporting diffusion of innovation through knowledge spill-overs (Wood and Dovey, 2015).

\section{Connectivity}

Connectivity describes the ease of flow within a system and across systems. In resilience both high and low connectivity can be desirable: the first facilitates diffusion of knowledge and recovery after disturbance, the second reduces the spread for disturbance and enables the preservation of pockets of memory (Marcus and Colding, 2014), although when this brings fragmentation, it affects negatively the system. In the urban form, both internal and external connectivity greatly affect people movement and the location and intensity of activities (Mehaffy et al., 2010): this reflects how lively and well-used places are (Remali et al., 2015). Because higher connectivity increases the points of contact and exchange between elements of the urban fabric, often the structure of connections between them matters even more than their nature (Salat and Bourdic, 2014).

\section{Redundancy}

In a system, redundancy is the availability of multiple components or pathways "performing the same, similar or backup functions" (Ahern, 2011 p.342) providing an insurance mechanism for anticipating change, damage or failure. A redundant system has lower probability to stall: in case of failure of one or more components, redundancy ensures continuity through availability of substitutes (Anderies, 2012). Notably, redundancy is not just about duplication of functions, as the degree of internal variability within each functional groups (Liao, 2012) is what gives the system the buffer capacity to use alternative resources or paths when the principal ones are lost (Anderies, 2012). Redundancy is a structural property of the urban form independent from any particular future scenario (Lhomme et al., 2013), but can help the survival of a system, when traumatic events occur.

\section{Modularity}

Modularity describes a system where functions or services are locally distributed and spread across decentralized sub-systems (Ahern, 2011). Internally, modules are tied by strong close-range internal connections while externally, they are kept together by relatively weak long-range connections (Salingaros, 2000). Individually, each module is structurally and functionally unitary and independent while, as a whole, modules are loosely interdependent (Anderies, 2012). This makes modules both autonomous elements and part of the system and enables them to aggregate to form new higherscale wholes without ever losing their individual identity (Salingaros, 2000). Hence, modularity is crucial for resilience. Thanks to a relative autonomy, each module or subsystem is sheltered from over-connectedness (Pickett et al., 2013): it can fail without severely affecting others and test novelty without disturbing other modules, thus ensuring stability. At the same time, the interdependency between modules allows innovation and knowledge to spread, promoting adaptation. In the urban form, modularity controls how urban elements interact with each other and across scales. Hence, it depends on the degree to which smaller components integrate, assemble, 
link or are autonomous from others. In a modular nested structure, "not even one scale can be missing, otherwise the whole system is unstable" (Salingaros, 2000 p.293)

\section{Efficiency}

The concept of efficiency in resilience, while often listed, is controversial. Several authors argue that efficiency is achieved at the expenses of diversity (Anderies, 2012), connectivity (Chelleri et al., 2012), redundancy and modularity (Novotny et al., 2010), thereby decreasing overall resilience. This is the case when efficiency is addressed to from a short-term perspective that seeks to simplify problems by optimizing processes and maximizing outputs at only one scale: in fact, in complex systems there is no optimal state and, due to scale interdependency, maximization of one element or process has unpredictable non-linear repercussions on others (Holling and Goldberg, 1971). Indeed, in complex systems, efficiency does not derive from a process of simplification but, conversely, it requires an increase in structural complexity at each and every scale (Salat and Bourdic, 2012). In the urban form, efficiency has to do with the hierarchic organization of different urban elements and requires that, at all scales, the same level of complexity is guaranteed. At this regard, several studies have found that this correspond to a scale-free urban structure, mathematically described with an inverse power that accounts for the frequency of an element's appearance in relation to its size (Salat and Bourdic, 2012). In an efficient urban structure, a long tail of smaller elements and tighter links is countered by progressively fewer larger elements and loose links (ibid.).

\section{RESILIENCE PROXIES ACROSS THE SCALES OF THE URBAN FORM}

As in all complex systems, also in cities, sub-systems (human, institutional and physical) operate across multiple scales. The urban form owes its ability to adapt to fluctuating economic, environmental and social circumstances to the dynamic interplay between scales. Thus, we will now observe how the five proxies manifest themselves across what we see as fundamental scales of the urban form (fig. 1). The adopted classification combines classical methods of urban morphology (Conzen, 1960, Caniggia and Maffei, 1979) with original research carried out at the Urban Design Studies Unit (UDSU) of University of Strathclyde (Porta and Romice, 2014, Mehaffy et al., 2010).

The smallest scale is that of the plot, a portion of land connected to, and accessible from, streets (Tarbatt, 2012, Caniggia and Maffei, 1979) and the smallest and most basic land-use unit (Panerai et al., 2004). Series of one or more plots served by the same street form the street edge. This is bound to the centrality (i.e. relative importance) of the street it sits on, which in turn, depends on the street's role within the larger network (Porta and Romice, 2014). Arrangements of street edges sitting on different streets - often characterized by different centrality - form blocks. Blocks are the result of the combination of one or more street edges/plots, and are carved out of streets. Streets are linear connective elements varying in centrality, according to their relative position within the broader street network. Several blocks and streets bounded by urban main roads or natural boundaries are called sanctuary areas (Appleyard et al., 1981, Mehaffy et al., 2010). Depending on their size, they can host a variety of forms, services and uses and allow a variety of movement types. When different sanctuary areas share core facilities and services of higher importance, they constitute higher order aggregates, variously defined as neighborhoods, districts, urban cells 
(Frey, 1999) etc. depending on culture and context. While plots and streets are homogeneous units of investigation, both street edges, blocks and sanctuary areas are aggregate elements defined in relation to other elements (the plot pattern, at the smallest scale, and the street network at the largest scale). Higher (i.e. region) and lower (i.e. buildings, dwelling units) scales are also of relevance to urban design, but will not be addressed specifically in this study.

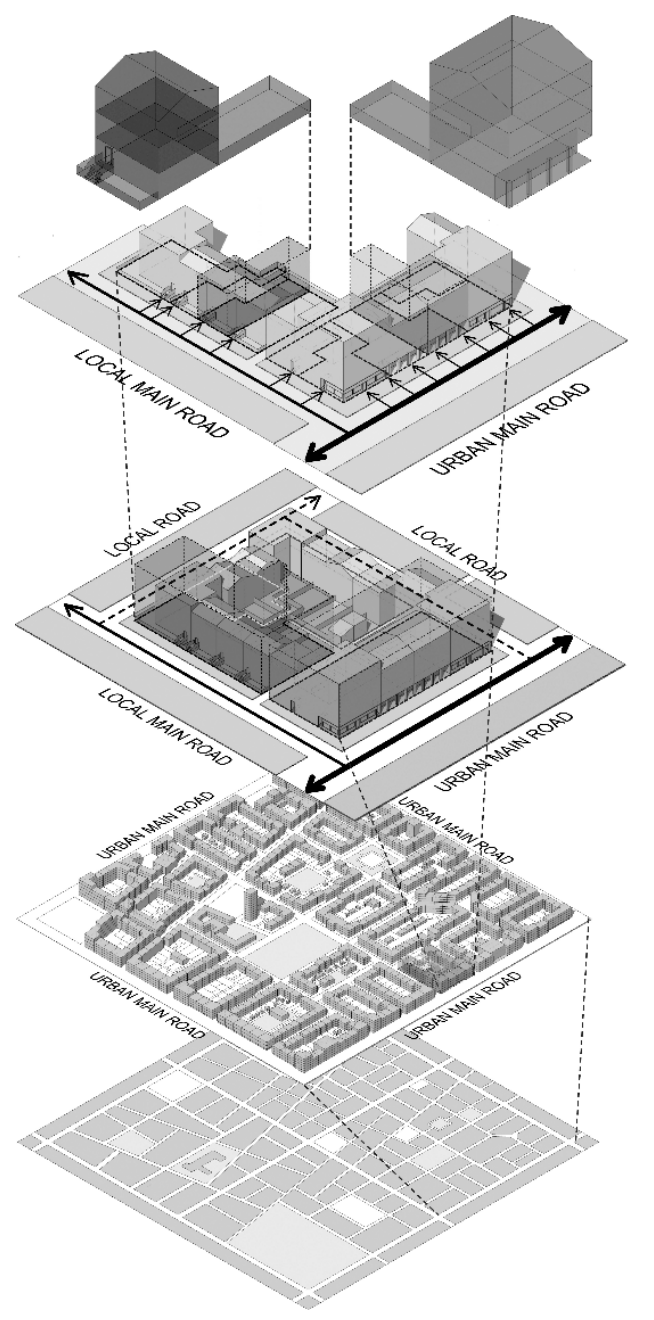

PLOT

a portion of land connected to, and accessible from streets, and the smallest and most basic land-use unit.

STREET EDGE

Series of one or more plots served by the same street and bound to the centrality of the street it sits on.

\section{BLOCK}

Arrangement of street edges sitting on different streets. They are result of the combination of one or more street edges/plots, and are carved out of streets.

\section{STREET}

Linear connective elements varying in centrality, according to their relative position within the broader street network.

\section{SANCTUARY AREA}

Assemblages of plots, street-edges, blocks and streets, they can host a variety of forms, services and uses and allow a variety of movement types.

\section{DISTRICT}

When different sanctuary areas share core facilities and services of higher importance, they constitute higher order aggregates, variously defined as districts.

Fig.1. Hierarchy of morphological scales. (Source: Authors)

\section{Resilience proxies at the plot scale}

Plots have a crucial role in building resilience (fig.2): as they can host a variety of functions vertically and horizontally, they are crucial for diversity. However, as functions tend to change quickly, the geometry of plots becomes crucial in its capacity to accommodate different functions in time (Kropf, 1996, Whitehand, 1979). In particular, the presence of a long tail of small plots countered by fewer large plots is signature of a complex efficient scale-free structure: small plots are generally more flexible to change of use and adaptation, reason why they are favourite location for creative industries of all types (Wood and Dovey, 2015); simultaneously small amounts of larger plots offer the perfect setting for more specialised functions. 
According to Salat et al. (2014) "A variety in sizes of plots provides investment opportunities for every budget and every investor, which creates a diversified market with a multiplicity of actors" ( $p .80)$, increasing the chances that similar functions are provided in different ways simultaneously, and hence redundancy: if one fails others can subsist, promoting the ability of places and people to self-organize and re-organize easily (Marcus and Colding, 2014). Over time this also allows the emergence of other types of diversity thus generating a higher level of mixité in terms of building ages, values, layouts and sizes, etc. (Jacobs, 1961). As each plot is occupied by an independent function and is subject to an autonomous ownership regime, to a large extent plots work as proper modular elements: they are individually, functionally and geometrically independent from other plots while at the same time somewhat connected to each other (as they rely all on the same network). However, modularity at the scale of plots significantly depends on plot geometry: with size comes a different capacity to aggregate or disaggregate, where larger plots are particularly disadvantaged, compared to small plots (Panerai et al., 2004, Habraken, 1998). Furthermore, simpler geometries (generally rectangular) are better suited to favor the emergence of coherent wholes. Finally, as plots represent the origin and destination to most trips, plot accessibility is important for connectivity: higher number of accessible plots, implies larger availability of different and independent destinations reachable within short distance or time (Marcus and Colding, 2011), hence higher internal connectivity.

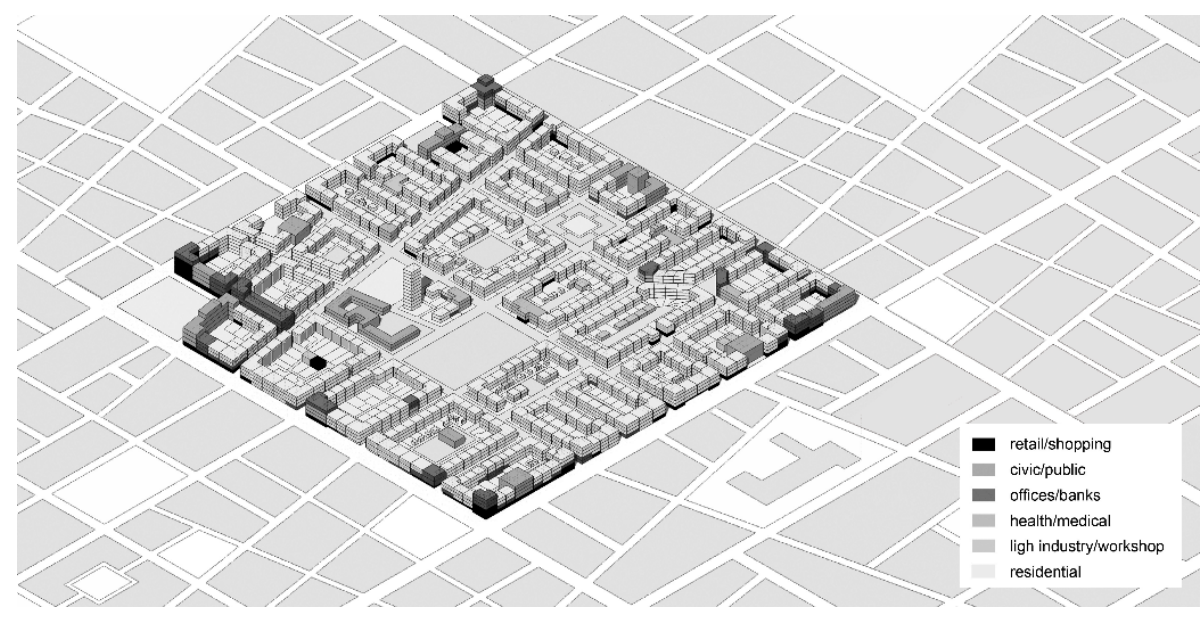

Fig.2. Resilience at the scale of plots (Source: Authors)

\section{Resilience proxies at the scale of street edges}

Street edges are the interface between streets and plots, and hence between public and private domains (Thwaites, 2013). Diversity of street edges is a reflection of the diversity of abutting streets but this "synchronisation" can be facilitated or impeded depending on the grain of its constituent plots, the distance between street intersections, and crucially by the level of "constitutedness" of the street (Van Nes and López, 2007), that is the extent to which building fronts and street are in close visual and functional relationship with each other. Generally, this comes through a gradual process of adaptation through time that leads to higher diversification (Porta and Romice, 2014): when there is good responsiveness between hierarchy of streets and plot pattern, street fronts become a constituent component of the complexity of the urban landscape, which in turn leads to higher efficiency. However, in much post-war 
development street edges were explicitly designed in order to be "unconstituted", reduced to an iteration at vast scale of very few types; that resulted in a drastic reduction of the number of different urban interfaces and a mismatch between plots and streets. As interfaces between streets and plots, street edges also control how different urban elements connect to each other (Thwaites et al., 2013). In this, street edges are crucial for modularity: the degree of autonomy of and interdependency between modules partly rests on the degree to which their borders are permeable to different kind of flows. Alexander et al. (1977), stressed extensively the fundamental role of edges and interface elements in the creation of coherent wholes. Again, depending on their "constitutedness", street edges can be "soft" and porous to exchange (active fronts, arcades etc.), or, conversely, limit interaction (setbacks, etc.) or even preclude any joining (high fences, blank fronts no access points, etc.), in which case, adjacent modules can be isolated despite their physical proximity (Gehl, 2011). The degree of permeability of street edges also depends on the presence of many or few access points and, in this sense it becomes very important for connectivity, particularly at the local scale. A greater number of tightly paced access points, made possible by the presence of many relatively narrow plots, increases accessible destinations, which is beneficial for social life (Romice et al., in print). Either ways, the desirable degree of permeability of street edges depends on street importance (fig.3). Street edges located onto major thoroughfares require greater permeability to support continuous interaction between public and private space. Conversely predominantly residential streets do not need the same intensity of exchange, therefore they can afford lower permeability.

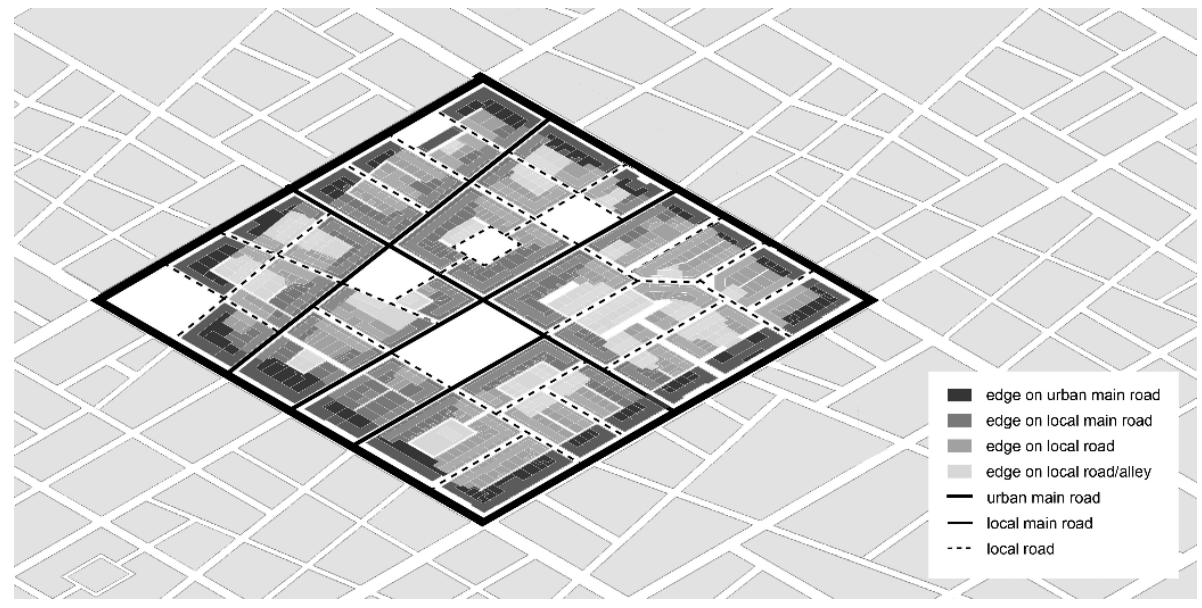

Fig.3. Resilience at the scale of street edges (Source: Authors)

\section{Resilience proxies at the block scale}

As aggregation of different street edges, blocks sizes depends on the pace of street intersections and their grain on the assemblage of plots. Both impact on the distribution of uses and activities and patterns of movement (fig.4). On the one hand, blocks constituted by one or very few super-plots have limited potential for diversity and redundancy, reduced accessibility and poor modular capacity to aggregate or subdivide. On the other hand, small-sized blocks invite greater diversity and variability in form and use and higher internal connectivity, particularly for pedestrians (Jacobs, 1961). At the same time, Salat and Bourdic (2012) argue that, if a more complex and efficient structure at all scales is to be established, along with many small blocks also 
several intermediate blocks and a few large blocks should be present; that ultimately favours diversity by creating the conditions for hosting specialist functions, or additional uses on them. Indeed, when large blocks are the result of the aggregation of street edges, they achieve greater complexity also to their core (collective gardens and workshops accessible from small streets or alleys).

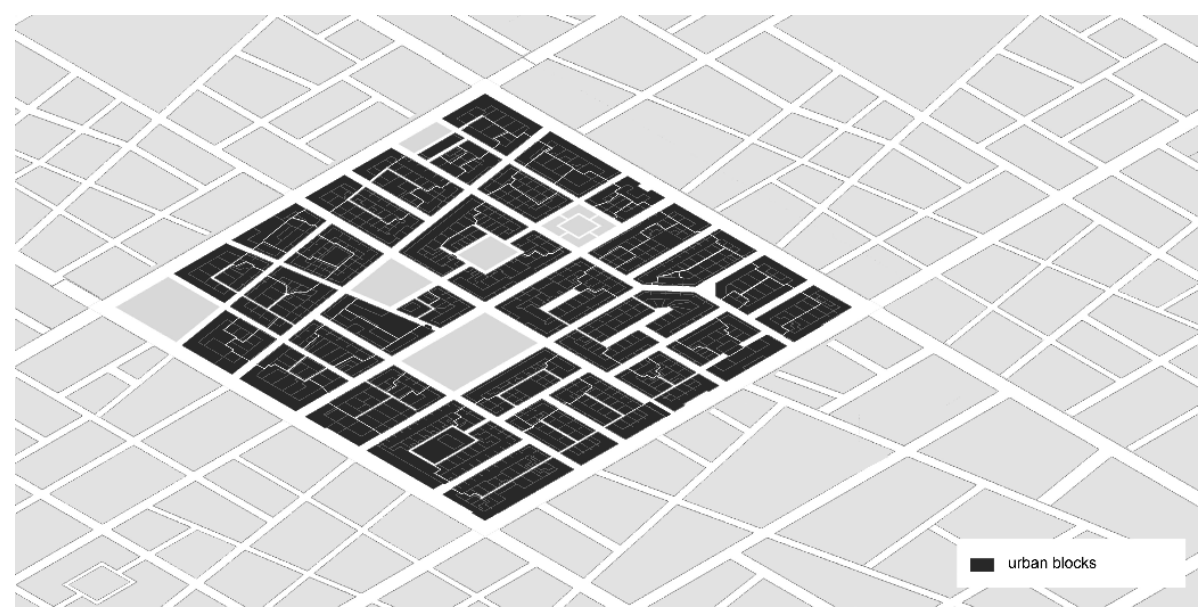

Fig.4. Resilience at the scale blocks (Source: Authors)

\section{Resilience proxies at the street scale}

By virtue of their location within the wider network, layout and individual geometrical properties, streets have different potential to foster resilience (Lhomme et al., 2013) (fig.5). The way a street is connected to all others in the overall street network locally and globally determines its centrality, which has a direct impact on its potential to support several interrelated dynamics which are crucial for urban life, such as location of retail and other land uses, size and form of plots, footfall, etc. (Porta et al., 2012). Street networks change and grow in time and tend to exhibit recursive characters: for example centrality tends to a power law, that combines global connectivity and local clustering (boccalettiStrano et al., 2012, Barthelemy, 2011). Such network architecture is structured as to include few urban mains links outreaching to the wider metropolitan and regional context, several local mains linking districts and neighborhoods, and many human-scale, walkable and dense local streets (Porta et al., 2006). Street networks are characterized by modularity when they feature many tightly connected sub-networks, linked to each other by means of "weak" ties that distribute flows across them. According to Webb and Bodin (2008) a balance between a modularity and connectivity should exist, so that many links are able to effectively connect to each other clusters of strongly connected nodes.

The configuration of street layout determines the connectivity of each street to its surrounding. A street layout characterized by a predominance of four-way intersections and few cul-de-sacs allows allow highest movement choice while creating a small number of pockets where movement is reduced. As an efficient street network should "make every location in the city easily accessible from any other location" (Salat and Bourdic, 2012 p.39), having a structure of this kind imparts greater resilience, compared to a situation where cul-de-sacs are predominant and even spatially proximate places result disconnected. Street layout configuration affects the redundancy of pathways linking destination (Lhomme et al., 2013), as this depends on 
the number of alternative paths available: interconnected grids feature higher redundancy while tree-like street networks generally have a very low degree of redundancy. When path redundancy is high, people have plenty of option in selecting a preferred path (Mehaffy, 2015). Additionally, path redundancy helps reduce the impact of losing key connections: when a street is closed or pedestrianized, flows manage to get around the interruption via secondary paths, something that is impossible in tree-like networks.

Geometrical properties of streets such as width, length and number of intersections reflect the importance and role of each street in its immediate surrounding and affect the nature and intensity of movement supported. In order to be interconnected, street segments should be numerous, short and feature many close-by intersections (Jacobs, 1961, Mehaffy, 2015, Carmona, 2010): more streets and more frequent intersections produce finer-mesh circulation and allow for multiple routes and frequent shortcuts. From this derives greater diversity and a greater scope for variability of use.

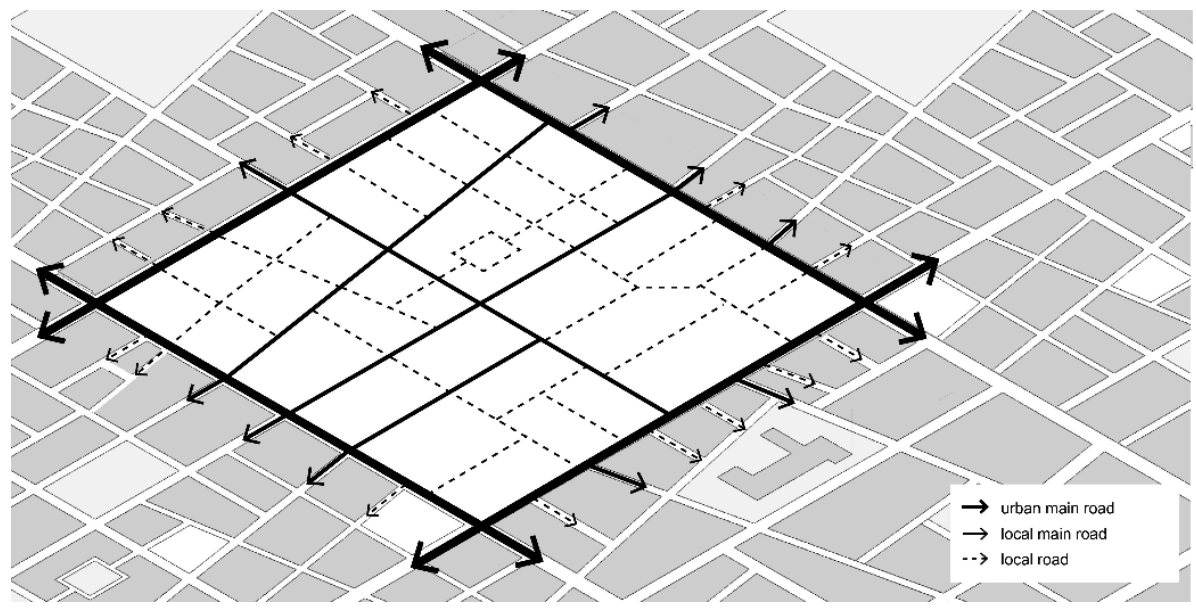

Fig.5. Resilience at the scale of streets (Source: Authors)

\section{Resilience proxies at the scale of sanctuary areas / districts}

"Sanctuary areas are anchors tying together small scale elements (blocks, streets, plots) to larger scale aggregates (districts, cities and regions); in a balanced dynamic between local needs and wider resources (fig.6). On the one hand a degree of autonomy permits to supply core needs without excessive dependence on outside sources, on the other interdependence with the wider urban context allows to access higher functions.

At the lower scales, sanctuary areas contribute to redundancy by ensuring variability in forms, a range of readily accessible uses and services and convenient internal connections. Hence, they should be easy to cross via tight local connections and their bounding streets should be easy to walk to. As very often uses tend to cluster around and extend along main streets in the form of local nodes, (Mehaffy et al., 2010) sanctuary areas need not to be too large and intersection between main streets should not be too far apart. Recent studies found that a good interval between main streets should not exceed 400 meters (Porta et al., 2014). 
At the larger urban scale, availability of diverse transport means and redundant modal options to move across sanctuary areas not only increases choice in terms of destinations and forms of mobility, but creates important synergies across scales: different infrastructures do not work independently but as multiplex networks reinforcing each other (Strano et al., 2015): as they meet, they create central nodes in the system (i.e. public transport hubs at busy street intersections) where interchanges are higher. This synergy allows each sanctuary area to share higher-level facilities or nodes hosting larger amount of less conventional or "district" uses or even speciality "metropolitan" uses (i.e. universities, large hospitals). Their existence is crucial for urban dynamics at district and metropolitan scale and no single sanctuary area alone would be able to support them. The way these nodes are distributed in space gives important cues on whether different areas benefit from a good balance between local, district and metropolitan nodes. A an equitable and diffused distribution of such nodes across different sanctuary areas ensures both choice and accessibility: the firsts should be very common and frequently interspersed, the second distributed less tightly, while the lasts in fewer and more centralized locations (Mehaffy, 2015, UTF and Rogers, 1999).

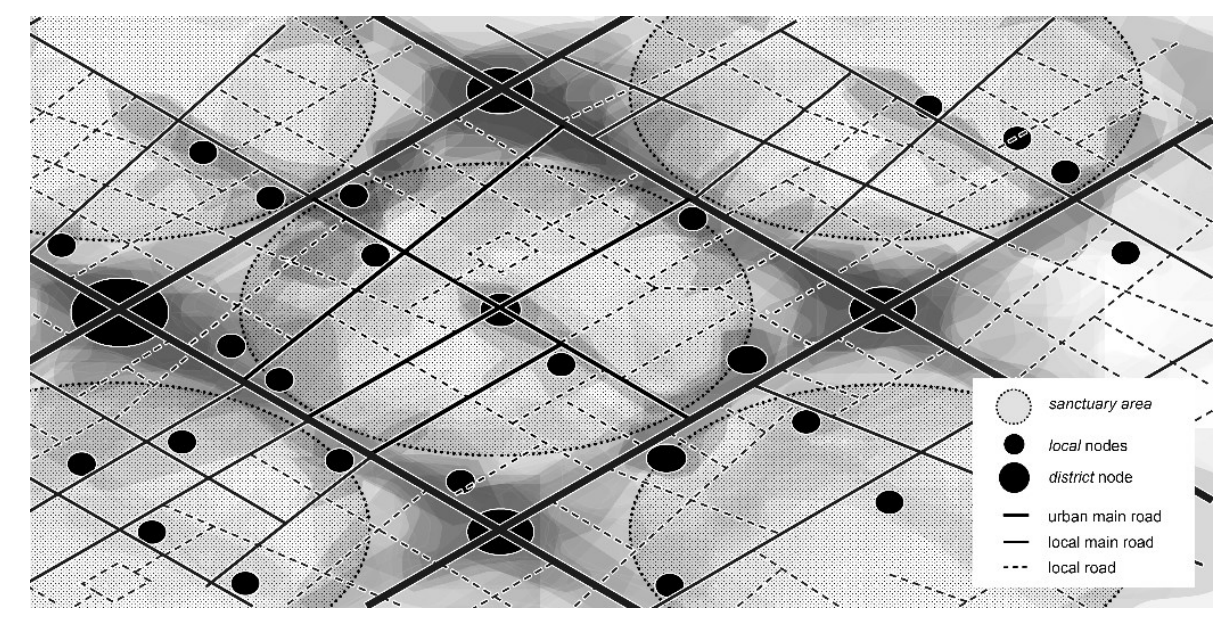

Fig.6. Resilience at the scale of sanctuary areas and districts (Source: Authors)

\section{CONCLUSIONS}

In this paper we focus on the physical dimension of cities as one component of the urban eco system that is relevant to its overall resilience. We acknowledge that, while the urban form might well be "the most tangible dimension of cities" this "does not exist in isolation, but within a framework of rules and regulations, actors and agents, networks and local cultures" (Marcus and Colding, 2011 p.4). Still, because intervention on the urban landscape is a highly time and resource intensive endeavor, resulting places are expected to have a long life ahead even when the rules of the game change.

Much research has documented the different degree of success with which cities and their parts have responded to structural change over time (Vale and Campanella, 2005, Panerai et al., 2004, Davis and Uffer, 2013). Since "there are urban forms that appear "inherently" more resilient to change over the long run than others" (Davis and Uffer, 2013 p.11) as if "resilience, as a design principle, was an implicit part of traditional construction knowledge" (Hassler and Kohler, 2014 p.119) we suggest that 
by understanding how form, at different scales, relates and contributes to resilience can help us to recover that knowledge.

Because the configuration of the urban environment has an influence on the resilience of the urban ecosystem as a whole, and since the urban landscape of cities is the object of urban design intervention, then urban design can enhance the resilience of such system by manipulating configuration and relationships between these elements. In this sense, the identified proxies could be deployed as general guiding principles for urban design aimed at supporting informed, evidence-based intervention on existing urban landscape of cities and in guiding the design of new ones. With this paper we aim at tracing the way forward along this avenue of research, which is still largely to be shaped in terms of both science and practice. One important task ahead is to find ways to measure the different proxies through a set of indicators specifically tailored to address the different scales of the urban form, something that would open important scenarios for evaluation and post-implementation monitoring of urban design projects. This work is part of a broader effort in developing a new approach to the design of resilient places and to the quantitative and qualitative monitoring of our cities.

\section{REFERENCES}

AHERN, J. 2011. From fail-safe to safe-to-fail: Sustainability and resilience in the new urban world. Landscape and Urban Planning, 100, 341-343.

ALEXANDER, C., ISHIKAWA, S., SILVERSTEIN, M. \& JACOBSON, M. 1977. A pattern language: towns, buildings. Constructions.

ALLAN, P. \& BRYANT, M. 2011. Resilience as a framework for urbanism and recovery. Journal of Landscape Architecture, 6, 34-45.

ANDERIES, J. M. 2012. Embedding built environments in social-ecological systems: resilience-based design principles. Building Research \& Information, 42, 130-142.

APPLEYARD, D., GERSON, M. S. \& LINTELL, M. 1981. Livable streets, protected neighborhoods, University of California Press.

BARTHELEMY, M. 2011. Spatial Networks. Physics Reports, 499, 1-101.

BATTY, M. 2013. The new science of cities, Mit Press.

BATTY, M. \& MARSHALL, S. 2009. Centenary paper: The evolution of cities: Geddes, Abercrombie and the new physicalism. Town Planning Review, 80, 551-574.

CANIGGIA, G. \& MAFFEI, G. L. 1979. Lettura dell'edilizia di base, Venezia., Marsilio Editori SPA.

CARMONA, M. 2010. Public places, urban spaces: the dimensions of urban design, Routledge.

CARPENTER, S. R., WESTLEY, F. \& TURNER, M. G. 2005. Surrogates for resilience of socialecological systems. Ecosystems, 8, 941-944.

CHELLERI, L., KUNATH, A., MINUCCI, G., OLAZABAL, M., WATERS, J. J. \& YUMALOGAVA, L. 2012. Multidisciplinary perspectives on urban resilience - Workshop Report, 1st edition. In: CHELLERI, L. \& OLAZABAL, M. (eds.). Bilbao, Spain.

CLOETE, C. 2012. Assessing urban resilience. Risk Analysis VIII, 167, 341. 
CONZEN, M. R. G. 1960. Alnwick, Northumberland: a study in town-plan analysis. Transactions and Papers (Institute of British Geographers), iii-122.

DAVIS, J. \& UFFER, S. 2013. EVOLVING CITIES, Exploring the relations between urban form resilience and the governance of urban form.

FELICIOTTI, A. in print. Socio-ecological resilience and urban design: defining the common ground and a way forward for practice. TERRA SPECTRA Planning studies

FELICIOTTI, A., ROMICE, O. \& PORTA, S. Masterplanning for Change: lessons and directions. In: MACOUN, M. \& MAIER, K., eds. 29th Annual AESOP 2015 Congress Definite Space - Fuzzy Responsibility, 2015 Prague, CZ. online version only, 30513065.

FIRLEY, E. \& GRÖN, K. 2014. The Urban Masterplanning Handbook, John Wiley \& Sons.

FREY, H. 1999. Designing the city: Towards a more sustainable urban form, London, E \& FN Spon.

GEHL, J. 2011. Life between buildings: using public space, Island Press.

HABRAKEN, N. 1998. Structure of the Ordinary; Form and Control in the Built Environment, edited by Jonathan Teicher. MIT Press, Cambridge, MA.

HASSLER, U. \& KOHLER, N. 2014. Resilience in the built environment. Building Research \& Information, 42, 119-129.

HOLLING, C. S. \& GOLDBERG, M. A. 1971. Ecology and planning. Journal of the American Institute of Planners, 37, 221-230.

JACOBS, J. 1961. The death and life of great American cities, Random House LLC.

KROPF, K. 1996. Urban tissue and the character of towns. Urban Design International, 1, 247-263.

LHOMME, S., SERRE, D., DIAB, Y. \& LAGANIER, R. 2013. Analyzing resilience of urban networks: A preliminary step towards more flood resilient cities. Natural Hazards and Earth System Science, 13, 221-230.

LIAO, K.-H. 2012. A Theory on Urban Resilience to Floods--A Basis for Alternative Planning Practices. Ecology and Society, 17, 48.

MARCUS, L. \& COLDING, J. Towards a spatial morphology of urban social-ecological systems. 18th International Seminar on Urban Form, 2011.

MARCUS, L. \& COLDING, J. 2014. Toward an integrated theory of spatial morphology and resilient urban systems. Ecology and Society, 19, 55.

MEHAFFY, M. 2015. Urban Form and Greenhouse Gas Emissions. $A+B E \mid$ Architecture and the Built Environment, 14, 1-192.

MEHAFFY, M., PORTA, S., ROFĖ, Y. \& SALINGAROS, N. 2010. Urban nuclei and the geometry of streets: The 'emergent neighborhoods' model. Urban Design International, 15, 22-46.

MOENCH, M., TYLER, S. \& LAGE, J. 2011. Catalyzing Urban Climate Resilience: Applying Resilience Concepts to Planning Practice in the ACCCRN Program (2009-2011), Institute for Social and Environmental Transition, International.

MONTGOMERY, J. 1998. Making a city: Urbanity, vitality and urban design. Journal of Urban Design, 3, 93-116. 
NOVOTNY, V., AHERN, J. \& BROWN, P. 2010. Water centric sustainable communities: planning, retrofitting and building the next urban environment, John Wiley \& Sons.

PANERAI, P., CASTEX, J. \& DEPAULE, J.-C. 2004. Urban forms: the death and life of the urban block, Routledge.

PICKETT, S. T., CADENASSO, M. L. \& MCGRATH, B. 2013. Resilience in ecology and urban design: Linking theory and practice for sustainable cities, Springer Science \& Business Media.

PORTA, S., CRUCITTI, P. \& LATORA, V. 2006. The network analysis of urban streets: a primal approach. Environment and Planning B: Planning and Design, 33, 705-725.

PORTA, S., LATORA, V., WANG, F., RUEDA, S., STRANO, E., SCELLATO, S., CARDILLO, A., BELLI, E., CÀRDENAS, F., CORMENZANA, B. \& LATORA, L. 2012. Street Centrality and the Location of Economic Activities in Barcelona. Urban Studies, 49, 1471-1488.

PORTA, S. \& ROMICE, O. 2014. Plot-based urbanism: towards time-consciousness in place-making. In: SONNE, W. (ed.) Dortmunder Vorträge zur Stadtbaukunst [Dortmunder Lectures on Civic Art]. Sulgen, DE.

PORTA, S., ROMICE, O., MAXWELL, J. A., RUSSELL, P. \& BAIRD, D. 2014. Alterations in scale: Patterns of change in main street networks across time and space. Urban Studies, 0042098013519833.

REMALI, A., PORTA, S., ROMICE, O. \& ABUDIB, H. 2015. Street quality, life and centrality in Tripoli. In: VAUGHAN, L. (ed.) Suburban Urbanities: Suburbs and the Life of the High Street. London: UCL Press.

ROMICE, O., THWAITES, K., PORTA, S. \& GREAVES, M. in print. City form and wellbeing. In: POL, E., NAVARRO, O. \& FLEURY-BAHI (eds.) The Handbook of Environmental Psychology and Quality of Life Research. Springer.

RUDLIN, D. \& FALK, N. 2009. Sustainable Urban Neighbourhood: building the 21st century home, Routledge.

SALAT, S. \& BOURDIC, L. 2012. Urban complexity, efficiency and resilience, INTECH Open Access Publisher.

SALAT, S. \& BOURDIC, L. 2014. Spatial Planning Principles \& Assessment Framework For Climate Adaptive \& Resilient Cities in China. International Workshop on Urban Adaptation to Climate Change. Beijing, People's Republic of China.

SALAT, S., BOURDIC, L. \& LABBE, F. 2014. Breaking Symmetries and Emerging Scaling Urban Structures: A Morphological Tale of 3 Cities: Paris, New York and Barcelona. International Journal of Architectural Research: ArchNet-IJAR, 8, 77-93.

SALINGAROS, N. A. 2000. Complexity and urban coherence. Journal of Urban Design, 5, 291-316.

STRANO, E., NICOSIA, V., LATORA, V., PORTA, S. \& BARTHÉLEMY, M. 2012. Elementary processes governing the evolution of road networks. Scientific Reports, 2.

STRANO, E., SHAI, S., DOBSON, S. \& BARTHELEMY, M. 2015. Multiplex networks in metropolitan areas: generic features and local effects. Journal of The Royal Society Interface, 12, 20150651.

TACHIEVA, G. 2010. Sprawl repair manual, Island Press.

TARBATT, J. 2012. The plot : designing diversity in the built environment : a manual for architects and urban designers, London, RIBA Publishing. 
THWAITES, K., MATHERS, A. \& SIMKINS, I. 2013. Socially restorative urbanism: the theory, process and practice of experiemics, Routledge.

THWAITES, K., PORTA, S., ROMICE, O. \& GREAVES, M. 2007. Urban sustainability through environmental design: approaches to time-people-place responsive urban spaces, Taylor \& Francis.

UTF, U. T. F. \& ROGERS, R. 1999. Towards an Urban Renaissance: The Report of the Urban Task Force Chaired by Lord Rogers of Riverside; Executive Summary, Urban Task Force.

VALE, L. J. \& CAMPANELLA, T. J. 2005. The resilient city: How modern cities recover from disaster, Oxford University Press.

VAN NES, A. \& LÓPEZ, M. J. Micro scale spatial relationships in urban studies: the relationship between private and public space and its impact on street life. Proceedings of the 6th Space Syntax Symposium (6SSS), Istanbul, Turkiye, June 12-15, 2007, 2007.

WEBB, C. \& BODIN, Ö. 2008. A network perspective on modularity and control of flow in robust systems. Complexity theory for a sustainable future, 85-118.

WHITEHAND, J. 1979. The study of variations in the building fabric of town centres: procedural problems and preliminary findings in southern Scotland. Transactions of the Institute of British Geographers, 559-575.

WOOD, S. \& DOVEY, K. 2015. Creative Multiplicities: Urban Morphologies of Creative Clustering. Journal of Urban Design, 1-23. 